\title{
An Investigation into the Impact of Information on Stock Price Volatilities in Vietnam
}

\author{
NGUYEN HUU HUY NHUT \\ University of Economics HCMC - nhut@ueh.edu.vn \\ NGUYEN KHAC QUOC BAO \\ University of Economics HCMC - nguyenbao@ueh.edu.vn \\ TRAN NGUYEN HUY NHAN \\ Joint Stock Commercial Bank for Foreign Trade of Vietnam (Vietcombank) - \\ nhantnh.hcm@vietcombank.com.vn
}

\section{ARTICLE INFO ABSTRACT}

Article history:

Received:

Nov. 17. 2014

Received in revised form:

Mar. 11. 2015

Accepted:

Jun. 28. 2015

Keywords:

budgetary slack, budget participation, budget emphasis, nonfinancial managerial accounting information, human aspects of budgeting
Based on the panel data of 22 stock tickers in the two porfolios VN30 and HNX30 during 2008-2014, the research empirically investigates the impact of information on stock price volatilities in Vietnam. Non-traditional data collection approach and OLS and GARCH $(1 ; 1)$ models, along the use of data on information supply measured by the number of disclosures of the studied stocks and data on information demand measured by the number of search attempts on Google by means of Google Trend allow the research findings to be distilled into clear recommendations, which show that: (i) Both information supply and demand do affect stock price volatilities; and (ii) More profound and significant impact has been produced by information demand; particularly, effects of market-level information demand are more powerful than those of stock-level information demand. 


\section{Introduction}

Stock market, the role of which has been appreciated as an attractive channel for investment, reflects investors' expectations about the economy. A wide diversity of information supply and quantities as well as the number of regular followers shows that information is truly a fine gem of the kind which is worth possession and sought for in the largest amounts. Estimating market development must be based on the level of investors' participation and degree of transparency and/or efficiency of the market with its active role in circulating capital. Such level of investors' participation and growth in the number can be measured through their information demands and analyses.

Prediction about accurate price and its volatilities has long been an intriguing topic in the financial domain. Various empirical studies address one issue that stock price is affected by such factors as interest rate, exchange rate, speculative behavior, etc. Yet, regarding participants in the market, a moderate group of investors, whose decisions can directly exert influence on the market, make purchase/sale orders absolutely dependent on stock information collected from Internet sources.

Many studies shift the focus on the role of information supply and demand in the market (Kihlstrom, 1974; Grossman \& Stiglitz, 1980; Radner \& Stiglitz, 1984; Allen. 1990), yet use different methods (including quantities of macroeconomic news and company's news in Broadtape and Wall Street Journal published by Dow Jones \& Company or information volume in the Reuters North American Wire system) for determining information flows. Based on our due recognition that Internet has revolutionized the information and affected securities brokerage activities, access to financial information, and the custom of searching for on-line information prior to the decision-making process of most Vietnamese investors; we, as Vlastakis \& Markellos (2012), approach a new type of dataset to proxy firm-specific demand of information on the basis of Internet search volume, which allows us to investigate degree of effects of information demand on the individual stock and overall market, respectively.

The paper aims at analyzing the impact of information supply and demand on stock price volatilities at firm level in particular and market level in general. Two reseach questions to be addressed comprise: (i) Do there exist effects of information supply/demand on the volatilities and trading volume in the stock market? and (ii) How do market states affect information supply/demand and trading volume? 


\section{Theoretical bases and studies on the relationship between information and stock price volatilities through Google Trends data}

The relationship between information flows and financial market has been much mentioned by financial economists. Ederington \& Lee (1993) found a strong nexus among scheduled macroeconomic news announcements, interest rate, and foreign exchange futures markets. Mixture of Distribution Hypothesis (MDH) has been considered as a bridge between the studies of Clark (1973), Epps and Epps (1973), and Tauchen and Pitts (1983). The MDH explains the relation between the volatility and trading volume by basing the overall effects of volume and returns on the underlying information process. Direct results from the MDH are observed components in the market, such as the long-lasting volatility, affected by information flow templates. The core of the MDH is the changes in prices and trading volume driven by information flows. Increasing prices may result from unexpected good news release, as opposed to the release of bad news, both of which are associated with the above average trading volume and simultaneously establish a new equilibrium.

In addition, the theory of Asymmetric Information addresses the relationship between information and stock market. The asymmetry of information on stock markets occurs either when one or more investors have more or better private/public information about a certain enterprise, or when enterprises or their managers obtain superior information to outside investors. Two most common consequences arising from asymmetric information are adverse selection and moral hazard (Investopedia), which may distort decisions on market participation of economic actors, or even result in market failures.

The information-market relationship has been approached with data from Google Trends - a tool that helps gauge search behavior and trends of Google users throughout the world. It not only shows "how often a particular search-term is entered relative to the total search-volume" by countries, language, or a specific period of time, but also allows users to compare two or more search terms (Wikipedia). Concerning companies, for example, which own different names besides their stock tickers such as Hoang Anh Gia Lai, HAG, or Hoang Anh Gia Lai VN, the query comparison feature provided by Google Trends enables the most popular keywords to be selected.

Google Trends data have been employed by Da et al. (2011a), who used search frequency in Google (Search Volume Index [SVI]) to formulate "a direct measure of 
investor intention", and conducted an investigation into the correlation between SVI with "existing proxies of investor attention." The authors found that "SVI: (i) is correlated with but different from existing proxies of investor attention, (ii) captures investor attention in a more timely fashion, and (iii) likely measures the attention of retail investor". In a sample of Russell 3000 stocks from 2004 to 2008, it was indicated that "an increase in SVI predicts higher stock prices in the next two weeks and an eventual price reversal within the year." SVI, as an estimator of investor attention, may be more efficiently applied than other common proxies for attention. By aggregating the volume of queries related to household finance and economic concerns, Da et al. (2011b) established an index labelled "Finance and Economic Attitudes Revealed by Search" (FEARS) to newly measure "investor sentiment." A more recent study by Da et al. (2011c) found that a change in SVI of a firm's product could predict unexpected announcements related to firm's revenue that were consistent with the forecasts and analyses.

Additionally, $\mathrm{Xu}$ (2012) applied time series data with the data from Google Trends and Yahoo Finance to predict weekly stock price changes. The research results demonstrated a statistically significant correlation between changes in stock prices and data on information demand extracted from Google Trends. In another relevant study by Huang et al. (2013), SVI was used as a proxy for information demand to extend its role in stock trading activities, "focusing on speculative ones, such as margin buying, short selling, and day trading." This paper signified a positive correlation between rises in Google search volume and trading volumes by individual investors. In addition, the research results "support the following hypotheses: (i) individuals, being uninformed, have a greater demand for information; and (ii) with more information collected from web sites, more investors engage in speculative," implying that by empirical observation of Google search volume, trading activities of individual investors may be predicted by market administrators. Furthermore, Fink \& Johann (2014) identified the impact of investor attention on stock's liquidity and turnover by means of Google search volume. They reported that the liquidity increased on high attention days, which was more pronounced for stocks with a lower level.

In short, data extracted from Google Trends through SVI has been accepted and widely used as a proxy for information demand (attention) of individual investors. As a new approach, hence, the paper employs the volume of searches on Google - one of 
the most popular information-seeking methods, using Google Trends' SVI as a proxy for information demand.

\section{Data and methodology}

\subsection{Research methodology}

Based on a similar study by Vlastakis \& Markellos (2012) that empirically employed data for the largest 30 stocks traded on the NYSE to examine information demand and supply at the firm and market levels, this empirical research is conducted on information supply and demand on stock price volatilities and trading volume for enterprises in the two porfolios VN30 and HNX30. Then using OLS technique, the study performs regression analysis of realized volatility.

$$
R V_{t}=\omega+\gamma \pi_{t}+\delta \phi_{t}+\zeta \xi_{t}+\eta \tau_{t}+\lambda v_{t}+\theta v_{t-1}+\psi R V_{t-1}+\varepsilon_{t}
$$

where $\omega$ is the constant; $\pi_{t}$ denotes information demand at interval $\mathrm{t} ; \phi_{t}$ denotes market-related information demand at interval $t ; \xi_{t}$ is firm-specific information supply at interval $\mathrm{t}$; $\tau_{t}$ is aggregate information supply at interval $\mathrm{t}$; $v_{t}$ is the market return at interval t.; and $\varepsilon_{t}$ is the error.

Realized volatility (RV) measure, most commonly addressed in multiple academic studies, is based on the accuracy and model-free nature (Andersen et al., 2001a; 2001b). In this study it is applied to the analysis and estimation of data series with reference to Andersen et al. (2001a), in which the realized daily equity return volatilities and correlations obtained from high-frequency intraday transaction prices on individual stocks are investigated along the use of the five-minute intraday returns. However, due to the lack of minute related data, we estimate the logarithmic daily returns and find that the estimated results can be accepted as stock price and trading volume in Vietnam' market in minute-based estimation are not highly volatile, compared to those on a daily basis. Then, weekly realized volatility is estimated by calculating the total square value of returns for each week. Realized volatility for week $\mathrm{t}$ is represented as follows:

$$
\mathrm{RV}_{\mathrm{t}}=\sum_{\mathrm{i}=1}^{\mathrm{N}} \mathrm{r}_{\mathrm{t}, \mathrm{i}}^{2}
$$


where $r_{t, i}^{2}$ denotes square return of $i$ for week $t$. Natural logarithm (Ln) of realized volatility (similar to realized volatility, abbreviated as $R V_{t}$ ) is taken, and accordingly calculated and applied to subsequent analyses.

Next, we carry out regression of GARCH, the essence of which is parameters in maximum likelihood estimation. Although the application of its variations is likely, GARCH $(1,1)$ has been found by a voluminous literature to be the most desirable.

$$
\begin{aligned}
& r_{t}=\mu+\lambda v_{t}+\varepsilon_{t}, \varepsilon_{t} \mid \Omega_{t-1} \sim N\left(0, \sigma_{t}^{2}\right) \\
& \sigma_{t}^{2}=\omega+\gamma \pi_{t}+\delta \phi_{t}+\zeta \xi_{t}+\eta \tau_{t}+\alpha \varepsilon_{t-1}^{2}+\beta \sigma_{t-1}^{2}
\end{aligned}
$$

where $r_{t}$ is the stock return in time $\mathrm{t} ; \mu$ is the constant; $\varepsilon_{t}$ are the serially uncorrelated errors of stock returns with mean zero; $\Omega_{t-1}$ denotes the information set; $\sigma_{t}^{2}$ is the conditional variance of $\varepsilon_{t} ; \pi_{t}$ is firm-specific information demand at interval $\mathrm{t}$; $\phi_{t}$ is market-related information demand at interval $t ; \xi_{t}$ is firm-specific information supply at interval $\mathrm{t}$; $\tau_{t}$ is aggregate information supply at interval $\mathrm{t}$; $v_{t}$ is the market return at interval t.

Regression of trading volume with information supply and demand is then carried out:

$$
V_{t}=\omega+\kappa\left|r_{t}\right|+\gamma \pi_{t}+\delta \phi_{t}+\zeta \xi_{t}+\eta \tau_{t}+\varepsilon_{t}
$$

where $V_{t}$ is the trading volume; $|\mathrm{rt}|$ is the absolute stock log return; $\pi_{t}$ denotes information demand at interval $\mathrm{t}$; $\phi_{t}$ is market-related information demand at interval t; $\xi_{t}$ is firm-specific information supply at interval $\mathrm{t}$; and $\tau_{t}$ is aggregate information supply at interval t.

A dummy variable is introduced to the model, denoting market states, and regression of volatilities with information supply and demand is accordingly conducted:

$$
\begin{aligned}
& R V_{t}=\omega+\gamma H_{t} \pi_{t}+\gamma L_{t} \pi_{t}+\delta H_{t} \phi_{t}+\delta L_{t} \phi_{t}+\zeta H_{t} \xi_{t}+\zeta L_{t} \xi_{t}+\eta H_{t} \tau_{t}+\eta L_{t} \tau_{t}+ \\
& \kappa\left|r_{t}\right|+\theta\left|r_{t-1}\right|+\psi R V_{t-1}+\varepsilon_{t}
\end{aligned}
$$

where $|\mathrm{rt}|$ is the absolute stock $\log$ return; $\pi_{t}$ denotes information demand at interval $\mathrm{t}$; $\phi_{t}$ is market-related information demand at interval $t ; \xi_{t}$ is firm-specific information supply at interval $\mathrm{t}$; and $\tau_{t}$ is aggregate information supply at interval $\mathrm{t}$. 


\subsection{Data}

The research employs the datasets on the weekly basis comprising information supply and demand, trading volumes and closing prices of 30 stock tickers in VN30, VNINDEX, 30 stock tickers in HNX30, and HNXINDEX as of July 31, 2014. Data selection is based on VN30 and HNX30, including stocks that have been screened and structured according to international practices (respecting capitalization, free-float stocks, and liquidity), which performs the market supply-demand relationship in the most precise manner. The surveyed period has been derived from the original study in which only a few representative tickers are used. Thus, comparing the two stock exchanges, we focus on VN30 and HNX30 of the most recent period, guided by the thought that these would best represent the exchanges.

Information supply presented in the study is measured by the total number of corporate information disclosed in the market through financial pages, and VNI is calculated by a total of information supply due to various reasons (in case of no disclosure of corporate information or statistical errors of financial pages, VNI of several specific days takes the value 0 , resulting in the difference in max and min values).

However, logarithm $(\ln )$ is taken to mitigate the data deviation. Apart from such, in the data collection process we find that insufficient information on supply, demand, and prices of some tickers cause a gross distortion of the regression results of HOSE and HNX; thus, for HOSE and information demand, the eliminated comprise FLC, ITA, MSN, OGC, IJC, CII, and GMD, and for information supply, the eliminated comprise HAG, HCM, CSM, BVH, EIB, and DRC along the newly listed stocks such as $\mathrm{CTG}, \mathrm{MBB}, \mathrm{HSG}$, and $\mathrm{VCB}$ (inadequate prices and returns). Accordingly, the stocks listed on HOSE to be researched include DPM, FPT, HPG, KDC, PPC, PVD, PVT, REE, SSI, STB, VIC, VNM, and VSH.

Similarly, those on HNX consist of ABC, SHB, LAS, VND, SHS, BVS, HUT, PLC, and $\mathrm{HMH}$, making a total of 22 stock tickers for the entire surveyed period between January 2008 and July 31, 2014 on a weekly basis.

Data on weekly information demand are obtained from Google Insights for Search, which provides Search Volume Index (SVI) for any query people have been entering by specific time and geographical areas. Concerning individual keywords, Da et al. (2011a) suggest that identifying search frequencies by the stock ticker proves 
preferable as opposed to the company name for three reasons. "First, investors may search the company name for reasons unrelated to investing ... Second, Google Trends does not allow non-alphabetical terms, so search data on companies such as p3Mqand p7\&Elevenq will be missing. Finally, different investors may search the same firm using several variations of its name." In this present study stock tickers are adopted as search keywords. For some cases we use the company name or its abbreviation due to more search attempts. Keyword searches for the company name or stock ticker are assumed to be random.

\section{Table 1}

Descriptive statistics of information demand

\begin{tabular}{lccccccccc}
\hline Stock & Max & Min & Mean & Median & Range & Std. dev. & CV & Skew & Kurt \\
\hline DPM & 100 & 49 & 78.43 & 78 & 51 & 7.99 & 0.10 & -0.41 & 1.23 \\
FPT & 100 & 15 & 48.43 & 51 & 85 & 13.67 & 0.28 & -0.13 & -0.04 \\
HPG & 100 & 0 & 54.12 & 53 & 100 & 19.06 & 0.35 & -0.63 & 1.35 \\
KDC & 100 & 0 & 28.33 & 28 & 100 & 22.12 & 0.78 & 0.43 & -0.31 \\
PPC & 100 & 14 & 41.50 & 28 & 86 & 27.17 & 0.65 & 0.77 & -0.93 \\
PVD & 100 & 51 & 76.27 & 74 & 49 & 8.95 & 0.12 & 0.29 & -0.16 \\
PVT & 100 & 27 & 68.25 & 71 & 73 & 19.84 & 0.29 & -0.40 & -1.04 \\
REE & 100 & 5 & 50.99 & 53 & 95 & 13.53 & 0.27 & -1.80 & 4.99 \\
SSI & 100 & 5 & 76.57 & 82 & 95 & 21.14 & 0.28 & -2.60 & 5.50 \\
STB & 100 & 47 & 73.46 & 74 & 53 & 12.04 & 0.16 & 0.15 & -0.77 \\
VIC & 100 & 4 & 25.30 & 27 & 96 & 13.12 & 0.52 & 0.85 & 3.08 \\
VNM & 100 & 3 & 37.99 & 39 & 97 & 19.36 & 0.51 & 0.17 & -0.50 \\
VSH & 100 & 34 & 57.80 & 56 & 66 & 12.43 & 0.21 & 0.68 & 0.19 \\
VNI & 101 & 37 & 67.37 & 67 & 64 & 11.10 & 0.16 & -0.01 & 1.15 \\
ABC & 100 & 9 & 40.83 & 42 & 91 & 12.70 & 0.50 & 1.31 & 0.31 \\
SHB & 100 & 8 & 33.18 & 31 & 92 & 13.57 & 1.02 & 1.48 & 0.41 \\
LAS & 100 & 19 & 45.29 & 42 & 81 & 16.91 & 1.34 & 1.71 & 0.37 \\
VND & 100 & 4 & 28.63 & 24 & 96 & 19.18 & 1.17 & 0.94 & 0.67
\end{tabular}




\begin{tabular}{lccccccccc}
\hline Stock & Max & Min & Mean & Median & Range & Std. dev. & CV & Skew & Kurt \\
\hline SHS & 100 & 4 & 30.45 & 20 & 96 & 22.05 & 1.13 & 0.38 & 0.72 \\
BVS & 27 & 4 & 11.50 & 10 & 23 & 5.04 & 1.29 & 1.18 & 0.44 \\
HUT & 100 & 24 & 41.72 & 41 & 76 & 7.08 & 2.49 & 15.60 & 0.17 \\
PLC & 100 & 5 & 31.12 & 28 & 95 & 13.74 & 1.14 & 1.89 & 0.44 \\
HMH & 100 & 17 & 43.55 & 40 & 83 & 13.53 & 0.77 & 0.44 & 0.31 \\
HNX & 100 & 5 & 38.13 & 33 & 95 & 19.75 & 0.74 & -0.17 & 0.52 \\
\hline
\end{tabular}

Source: Authors' calculations

\section{Table 2}

Descriptive statistics of information supply

\begin{tabular}{lccccccccc}
\hline Stock & Max & Min & Mean & Median & Range & Std. dev. & CV & Skew & Kurt \\
\hline DPM & 7 & 0 & 1.63 & 1 & 7 & 1.48 & 0.95 & 0.63 & 0.91 \\
FPT & 64 & 0 & 3.40 & 2 & 64 & 4.29 & 8.62 & 115.37 & 1.26 \\
HPG & 9 & 0 & 1.89 & 2 & 9 & 1.62 & 0.92 & 1.10 & 0.86 \\
KDC & 36 & 0 & 2.45 & 2 & 36 & 2.65 & 6.44 & 75.21 & 1.08 \\
PPC & 54 & 0 & 1.59 & 1 & 54 & 3.20 & 12.93 & 208.82 & 2.01 \\
PVD & 36 & 0 & 1.94 & 2 & 36 & 2.44 & 8.37 & 110.42 & 1.26 \\
PVT & 11 & 0 & 1.66 & 1 & 11 & 1.71 & 1.95 & 5.73 & 1.03 \\
REE & 35 & 0 & 1.84 & 1 & 35 & 2.53 & 7.19 & 86.20 & 1.38 \\
SSI & 16 & 0 & 1.97 & 1 & 16 & 2.15 & 2.22 & 8.20 & 1.09 \\
STB & 81 & 0 & 3.69 & 3 & 81 & 4.97 & 11.23 & 171.35 & 1.35 \\
VIC & 13 & 0 & 2.33 & 2 & 13 & 2.14 & 1.51 & 3.55 & 0.92 \\
VNM & 57 & 0 & 2.92 & 2 & 57 & 3.59 & 10.26 & 149.97 & 1.23 \\
VSH & 61 & 0 & 2.29 & 2 & 61 & 3.62 & 12.57 & 201.82 & 1.58 \\
VNI & 5500 & 10 & 572.24 & 540 & 5490 & 351.89 & 8.11 & 111.33 & 0.61 \\
ABC & 12 & 0 & 3 & 2 & 12 & 2.43 & 1.14 & 1.17 & 0.81 \\
SHB & 8 & 0 & 2.5 & 2 & 8 & 1.56 & 0.84 & 0.71 & 0.62
\end{tabular}




\begin{tabular}{lccccccccc}
\hline Stock & Max & Min & Mean & Median & Range & Std. dev. & CV & Skew & Kurt \\
\hline LAS & 9 & 0 & 2 & 2 & 9 & 1.85 & 1.04 & 1.20 & 0.92 \\
VND & 9 & 0 & 1 & 1 & 9 & 1.50 & 1.54 & 3.27 & 1.50 \\
SHS & 10 & 0 & 0.5 & 2 & 10 & 1.57 & 1.40 & 3.20 & 3.15 \\
BVS & 9 & 0 & 1.5 & 1 & 9 & 1.55 & 1.38 & 2.38 & 1.04 \\
HUT & 12 & 0 & 1 & 2 & 12 & 1.97 & 1.71 & 3.98 & 1.97 \\
PLC & 10 & 0 & 0.5 & 1 & 10 & 1.96 & 1.39 & 1.88 & 3.92 \\
HMH & 16 & 0 & 0.5 & 3 & 16 & 2.52 & 1.16 & 2.04 & 5.05 \\
HNX & 1833.33 & 66.67 & 350.00 & 633.33 & 1766.67 & 258.92 & 0.88 & 2.44 & 0.74 \\
\hline
\end{tabular}

Source: Authors' calculations

As seen from the statistical results, information supply and demand of the stocks produce relatively low normal distribution; the difference between max and min values is large, which is evidenced by the fact that disclosure of corporate information was not frequent, causing interruption to information search. Next, the Jarque-Bera test for information supply and demand is conducted, indicating that only two variables of information demand (FPT and PVD) are normally distributed, whereas no normal distribution is revealed by any variables of information supply.

\section{Results and discussion}

Due to a small number of normally distributed variables, logarithm of the variables is taken, and a stationarity test is conducted. For this process, the research uses both ADF (Dickey \& Fuller, 1979) and PP (Phillips \& Perron, 1988) tests.

\section{Table 3}

Stationarity test for information demand

\begin{tabular}{cccc}
\hline Information demand & ADF test & PP test & Result \\
\hline DPM & $-4.37 * * *$ & $-3.458^{* * *}$ & Stationary \\
FPT & $-2.858^{*}$ & $-2.805^{*}$ & Stationary \\
HPG & $-3.077^{* *}$ & $-3.094^{* *}$ & Stationary
\end{tabular}




\begin{tabular}{|c|c|c|c|}
\hline Information demand & ADF test & PP test & Result \\
\hline $\mathrm{KDC}$ & $-4.592 * * *$ & $-3.776 * * *$ & Stationary \\
\hline $\mathrm{PPC}$ & $-2.593^{*}$ & $-2.795 *$ & Stationary \\
\hline PVD & $-2.858^{*}$ & $-2.976^{* *}$ & Stationary \\
\hline PVT & $-3.856 * * *$ & $-2.864 *$ & Stationary \\
\hline REE & $-3.466 * *$ & $-3.438 * *$ & Stationary \\
\hline SSI & $-3.519 * * *$ & $-2.599 *$ & Stationary \\
\hline STB & $-2.924 * *$ & $-2.606^{*}$ & Stationary \\
\hline VIC & $-5.499 * * *$ & $-4.487 * * *$ & Stationary \\
\hline VNM & $-4.715 * * *$ & $-3.969 * * *$ & Stationary \\
\hline VSH & $-4.486 * * *$ & $-3.746 * * *$ & Stationary \\
\hline VNI & $-3.856 * * *$ & $-2.864 *$ & Stationary \\
\hline $\mathrm{ACB}$ & $-4.698 * * *$ & $-4.568 * * *$ & Stationary \\
\hline SHB & $-4.732 * * *$ & $-3.141 * *$ & Stationary \\
\hline LAS & $-3.094 * *$ & $-3.108 * *$ & Stationary \\
\hline VND & $-4.014 * * *$ & $-3.103 * *$ & Stationary \\
\hline SHS & $-3.703 * * *$ & $-2.864 *$ & Stationary \\
\hline BVS & $-3.660 * * *$ & $-3.127 * *$ & Stationary \\
\hline HUT & $-3.108 * *$ & $-3.359 * *$ & Stationary \\
\hline PLC & $-3.110 * *$ & $-3.591 * * *$ & Stationary \\
\hline $\mathrm{HMH}$ & $-3.484 * * *$ & $-3.519 * * *$ & Stationary \\
\hline HNX & $-3.630 * * *$ & $-3.959 * * *$ & Stationary \\
\hline
\end{tabular}

Based on the original study by Vlastakis \& Markellos (2012), OLS regression is applied to Eq. (1), (2), (3), and (4). The following table presents the Newey-West HAC standard errors and covariances test results. 


\section{Table 4}

Results of OLS regression between implied volatility of stock prices and information supply and demand (Eq. 1)

\begin{tabular}{|c|c|c|c|c|c|c|c|c|}
\hline Stock & $\Omega$ & $\gamma$ & $\delta$ & $\zeta$ & $\eta$ & $\lambda$ & $\theta$ & $\psi$ \\
\hline DPM & $0.0013 * * *$ & & $0.000176^{* * *}$ & & & & & $0.479 * * *$ \\
\hline FPT & $0.000827 * * *$ & & $-0.000272 * *$ & & & & & $0.637 * * *$ \\
\hline HPG & $0.00162 * * *$ & & $0.0000937 * * *$ & & & & $-0.0047 * *$ & $0.47 * * *$ \\
\hline $\mathrm{KDC}$ & $0.00138 * *$ & & $-0.000215^{* * *}$ & & & & & $0.457 * * *$ \\
\hline PPC & $0.00202 * *$ & & $-0.000318^{* * *}$ & $0.00068 * *$ & & $0.000637 * *$ & & $0.449 * * *$ \\
\hline PVD & & $-0.000068^{* *}$ & $0.0000883^{* * *}$ & & & & & $0.984 * * *$ \\
\hline PVT & & & & & & & & $0.976 * * *$ \\
\hline REE & & $-0.00078^{*}$ & $-0.0000471^{* *}$ & & & & & $0.988 * * *$ \\
\hline SSI & & & $-0.0000369 * * *$ & & $-0.0000716^{* *}$ & & & $0.979 * * *$ \\
\hline STB & & $-0.000096^{* *}$ & $0.0000105^{* * *}$ & & & & & $0.976 * * *$ \\
\hline VIC & & $-0.000229 * *$ & $0.0000224 * * *$ & & & $-0.00083 * *$ & & $0.966 * * *$ \\
\hline VNM & & $-0.00009 * * *$ & & & $0.0000263 *$ & $0.000339^{*}$ & & $0.983 * * *$ \\
\hline VSH & $0.00147 * *$ & & $-0.000161 * * *$ & & & & & $0.437 * * *$ \\
\hline $\mathrm{ACB}$ & $0.00204 * * *$ & & & & & $0.00606^{* * *}$ & & $0.444 * * *$ \\
\hline SHB & & & $0.0000302 *$ & & & & & $0.884 * * *$ \\
\hline LAS & $0.000196^{* *}$ & $0.00061^{*}$ & $0.0000509 * *$ & $-0.0000311^{*}$ & & & & $0.881 * * *$ \\
\hline VND & & $0.0000669 * *$ & & & & & & $0.983 * * *$ \\
\hline SHS & & & $0.0000218^{*}$ & & & & & $0.978 * * *$ \\
\hline BVS & & & $0.0000474 * *$ & & & & & $0.985 * * *$ \\
\hline HUT & & $0.000531 * *$ & & & & $-0.000758^{*}$ & & $0.965 * * *$ \\
\hline PLC & & & $0.0000203 * *$ & $0.0000384 * * *$ & & & $0.000313^{*}$ & $0.98 * * *$ \\
\hline HMH & $0.00148 * *$ & & & & & & & $0.433 * * *$ \\
\hline
\end{tabular}

Note: This table presents the Newey-West HAC standard errors and covariances test results. $\omega$ is the constant; $\gamma$ and $\delta$ are firm-specific information demand and market-related information demand respectively; $\zeta$ and $\eta$ are firm-specific information supply and market-related information supply respectively; $\lambda$ is the market return; $\theta$ is the coefficient for its first lag; $\psi$ is the coefficient for lag of implied volatility. Only $90 \%$ statistically significant variables are presented in the table.

$*, * *$, and $* *$ denote that the null is rejected at the $10 \%, 5 \%$, and $1 \%$ level, respectively. 
Concerning HOSE, firm-specific information demand and/or supply is a statistically significant independent variable among five cases, whereas 11 cases are reflected by market-related information demand and/or supply. However, while coefficients for market-related information demand and characteristics of information demand are not well noted, the impact of information supply is consistent with earlier positive results.

Given HNX, market-related information demand is statistically significant among five out of nine cases, whereas three out of nine cases are revealed by firm-specific information demand. In contrast, firm-specific information supply and market-related information supply are not statistically significant even though most of the cases regarding market-related information supply and its characteristics might be well noted. As originally intended, RV reveals high stability along the majority of statistically significantly positive coefficients for the first lag. The results accordingly indicate that market-related information demand is robust in its relation to RV and that information supply and characteristics of information demand are also significant but not clearly defined as for the two security exchanges.

Kalev et al. (2004) and Bomfim (2001) utilized GARCH and intraday realized volatility models. Kalev et al. (2004) implied that modelling information-volatility relation based on conditional heteroscedasticity is considered greater improvement than any prior process that aims at estimating unconditional volatility, for example, the absolute daily market return. Although the approach is believed to produce less accuracy than the realized volatility previously applied due to more data required, its advantages are such that it allows the possibility of modelization in terms of mean and variance at the same period and overcomes the heteroscedasticity in a direct manner. Additionally, since using GARCH has been well documented in finance, we employ conditional volatility in $\operatorname{GARCH}(1,1)$ model. The results are presented in Table 5.

\section{Table 5}

Estimated results of $\operatorname{GARCH}(1,1)$ with information supply and demand (Eq. 2)

\begin{tabular}{|c|c|c|c|c|c|c|c|c|c|}
\hline Stock & $\Omega$ & $\alpha$ & $\beta$ & $\Gamma$ & $\delta$ & $\zeta$ & $\eta$ & $\mu$ & $\lambda$ \\
\hline DPM & $-11.08 * * *$ & $1.19^{* * *}$ & & $0.756^{*}$ & $-0.251^{*}$ & & & $0.00410 * * *$ & $0.0526 * * *$ \\
\hline FPT & $-11.24 * * *$ & $1.279 * * *$ & & $2.409^{*}$ & $2.425 *$ & & & $0.00487 * * *$ & $0.0558 * * *$ \\
\hline HPG & $-10.55 * * *$ & $1.208 * * *$ & & & $-1.178^{*}$ & & & & $0.0471 * * *$ \\
\hline $\mathrm{KDC}$ & $-11.00 * * *$ & $1.257 * * *$ & & $2.972 * * *$ & $2.192 * *$ & & & & $0.0314 * * *$ \\
\hline PPC & $-9.76^{* * *}$ & $1.277^{* * *}$ & $-0.138 * *$ & & & & & $-0.0011^{*}$ & $0.0568 * * *$ \\
\hline
\end{tabular}




\begin{tabular}{|c|c|c|c|c|c|c|c|c|c|}
\hline Stock & $\Omega$ & $\alpha$ & $\beta$ & $\Gamma$ & $\delta$ & $\zeta$ & $\eta$ & $\mu$ & $\lambda$ \\
\hline PVD & $-10.47 * * *$ & $1.043 * * *$ & & $2.333 * *$ & $0.0894 *$ & & & $-0.00226^{* * *}$ & $0.0574 * * *$ \\
\hline PVT & $-10.05 * * *$ & $1.161^{* * *}$ & & & & & & $-0.00808 * * *$ & $0.0493 * * *$ \\
\hline REE & $-10.64 * * *$ & $1.262 * * *$ & & & & & $-0.832 *$ & & $0.0632 * * *$ \\
\hline SSI & $-16.07 * * *$ & $0.129 * * *$ & $0.294 * * *$ & $-6.531 * * *$ & $-6.531 * * *$ & $2.364 * * *$ & $-1.051 * *$ & $-0.000366 * * *$ & $1.000 * * *$ \\
\hline STB & $-19.47 * * *$ & $0.272 * * *$ & $0.779 * * *$ & $4.785 * * *$ & $4.785 * * *$ & $3.582 * * *$ & $-2.759 * * *$ & $-0.000558 * * *$ & $0.0999 * * *$ \\
\hline VIC & $-11.63 * * *$ & $1.207 * * *$ & $0.114 * *$ & $1.375^{*}$ & $0.284 * *$ & & & $-0.00352 * * *$ & $0.0506^{* * *}$ \\
\hline VNM & $-14.25^{* * *}$ & $1.118^{* * *}$ & $0.202 * * *$ & & & & & $-0.00456^{* * *}$ & $0.0475 * * *$ \\
\hline VSH & $-10.58 * * *$ & $1.042 * * *$ & & & & & & $0.00146^{* *}$ & $0.0517 * * *$ \\
\hline $\mathrm{ACB}$ & $-12.74 * * *$ & & $0.641 * * *$ & $-2.416^{* * *}$ & $-0.738 * * *$ & $-0.931 * * *$ & $1.585 * * *$ & $-0.00142 * * *$ & $0.992 * * *$ \\
\hline SHB & $-13.92 * * *$ & $0.198 * * *$ & $0.479 * * *$ & & $0.248 * * *$ & $-0.904 * * *$ & $-1.362 * * *$ & $-0.000938 * * *$ & $1.001 * * *$ \\
\hline LAS & $-10.27 * * *$ & & & & $0.351 * * *$ & & & & $0.989 * * *$ \\
\hline VND & $-9.29 * * *$ & & $0.410 * * *$ & & & & & & $0.891 * * *$ \\
\hline SHS & $-16.41 * * *$ & $0.169^{* * *}$ & $0.72 * * *$ & $-4.273 * * *$ & $3.612 * * *$ & & & $-0.00053 * * *$ & $0.997 * * *$ \\
\hline BVS & $-22.57 * * *$ & $0.431 * * *$ & $0.631 * * *$ & $-4.987 * * *$ & $9.978 * * *$ & $5.066 * * *$ & & $-0.00042 * * *$ & $0.999 * * *$ \\
\hline HUT & $-21.82 * * *$ & $0.0287 * * *$ & $0.916^{* * *}$ & $10.27 * * *$ & $-4.418 * * *$ & $3.715^{* * *}$ & & $-0.000437 * * *$ & $0.995 * * *$ \\
\hline PLC & $-22.19^{* * *}$ & & $0.919^{* * *}$ & & $-3.931 * * *$ & & $-1.348 * * *$ & $-0.000221 * * *$ & $0.985 * * *$ \\
\hline $\mathrm{HMH}$ & $-14.82 * * *$ & $0.298 * * *$ & & & $0.562 * * *$ & $1.735 * * *$ & $-3.282 * * *$ & $-0.000748 * * *$ & $0.998 * * *$ \\
\hline
\end{tabular}

Note: $r_{t}$ is the stock return in time $\mathrm{t}$; $\mu$ is the constant; $\varepsilon_{t}$ are the serially uncorrelated errors of stock returns with mean zero; $\Omega_{t-1}$ denotes the information set; $\sigma_{t}^{2}$ is the conditional variance of $\varepsilon_{t} ; \pi_{t}$ is firm-specific information demand at interval $\mathrm{t} ; \phi_{t}$ is market-related information demand at interval $\mathrm{t} ; \xi_{t}$ is firm-specific information supply at interval $\mathrm{t} ; \tau_{t}$ is aggregate information supply at interval $\mathrm{t}$; $v_{t}$ is the market return at interval $\mathrm{t}$.

$*, * *$, and $* *$ denote that the null is rejected at the $10 \%, 5 \%$, and $1 \%$ level, respectively.

Firm-specific information demand, as for HOSE, with both positive and negative signs is a statistically significant independent variable among seven out of 13 cases, whereas the figure is eight for market-related information demand with positive signs. Information supply does not produce a clear sign as the firm-specific one reveals positive signs for only two cases, and the whole set of information supply, only three cases. Similarly, regarding HNX, firm-specific and market-related information demands are two statistically significant variables; particularly, the market-related one (eight out nine cases are significant) reveals five out of eight cases with positive signs. 
Firm-specific and market-related information supplies are statistically significant but not robust, as evidenced by the infrequent information supply in the market.

It is evident from the Pearson's correlation analysis that positive relationships are held between trading volume and information demand, and both market-related information demand and its characteristics. The results are also equally true for volatilities; the correlation between the trading volume and information demand is more (less) significant than that at the whole market (firm) level.

\section{Table 6}

Pearson's correlation between firm-specific and market-related information demand and trading volume

\begin{tabular}{cccccc}
\hline Stock & $\begin{array}{c}\text { Firm-specific } \\
\text { demand }\end{array}$ & $\begin{array}{c}\text { Market-related } \\
\text { demand }\end{array}$ & Stock & $\begin{array}{c}\text { Firm-specific } \\
\text { demand }\end{array}$ & $\begin{array}{c}\text { Market-related } \\
\text { demand }\end{array}$ \\
\hline DPM & $0.3201^{*}$ & $0.1888^{*}$ & REE & -0.0602 & $0.1892^{*}$ \\
FPT & $0.3427^{*}$ & $0.3834^{*}$ & SSI & 0.0750 & $0.3085^{*}$ \\
HPG & 0.0074 & $0.3350^{*}$ & STB & $0.6394^{*}$ & $0.6748^{*}$ \\
KDC & $0.3571^{*}$ & $0.4773^{*}$ & VIC & -0.977 & $-0.1430^{*}$ \\
PPC & -0.0376 & $0.1598^{*}$ & VNM & 0.0085 & $0.1113^{*}$ \\
PVD & 0.0561 & $0.1766^{*}$ & VSH & 0.0481 & 0.0265 \\
PVT & 0.0205 & 0.0205 & & & 0.1183 \\
ACB & $-0.1728^{*}$ & 0.0386 & SHB & 0.0783 & $-0.0666^{*}$ \\
LAS & $-0.1965^{*}$ & $0.1725^{*}$ & VND & $0.1406^{*}$ & $0.5044^{*}$ \\
SHS & 0.0409 & 0.0686 & BVS & $0.1981^{*}$ & 0.1443 \\
HUT & -0.0342 & 0.0161 & PLC & 0.0414 & \\
HM & 0.2505 & 0.0117 & & & \\
H & & & & & \\
\hline
\end{tabular}

Finally, we analyze the effects of information demand on performance of each individual stock based on the trading volume. The volume is estimated by the number of stocks traded within one week to act in accordance with data on information supply and/or demand. Logarithm of the trading volume is accordingly taken. 


\section{Table 7}

Results of OLS regression between trading volume, stock return, and information supply/demand (Eq. 3)

\begin{tabular}{|c|c|c|c|c|c|c|}
\hline Stock & $\Omega$ & $\kappa$ & $\Gamma$ & $\delta$ & Z & $\eta$ \\
\hline DPM & $-0.179 * * *$ & $4.635 * * *$ & $0.705 * * *$ & $-0.169 *$ & & \\
\hline FPT & & & & $0.506^{* * *}$ & & \\
\hline HPG & $-0.27 * * *$ & $5.644 * * *$ & $-1.634 * * *$ & $1.300 * * *$ & $0.127^{*}$ & $0.167^{*}$ \\
\hline $\mathrm{KDC}$ & $0.163 * * *$ & $3.3884 * * *$ & & $1.183 * * *$ & & \\
\hline PPC & $-0.266 * * *$ & $4.992 * * *$ & $0.554 * *$ & $0.547 * * *$ & & \\
\hline PVD & $-0.158 * * *$ & $3.519 * * *$ & $0.333 * *$ & $0.346 * *$ & $0.191 * * *$ & \\
\hline PVT & $-0.203 * * *$ & $3.700 * * *$ & $1.058 * * *$ & & & \\
\hline REE & $-0.144^{*}$ & $2.905 * * *$ & & $1.397 * * *$ & & $0.196 * * *$ \\
\hline SSI & $-0.109 * *$ & $2.074 * * *$ & & $1.223 * * *$ & $0.102 *$ & \\
\hline STB & $-0.142 * *$ & $3.680 * * *$ & $0.325 * *$ & $1.120 * * *$ & $0.306 * * *$ & $-0.186^{* *}$ \\
\hline VIC & & & $0.488 * * *$ & & $0.159 * *$ & \\
\hline VNM & $-0.282 * * *$ & $8.688 * * *$ & & $0.433 * * *$ & & $0.161 * *$ \\
\hline VSH & $0.144 * *$ & $3.873 * * *$ & $1.082 * * *$ & $0.525 * * *$ & $0.148 *$ & $0.166^{* *}$ \\
\hline $\mathrm{ACB}$ & $0.219 * * *$ & $4.104 * * *$ & $-0.505^{*}$ & $0.215^{*}$ & $-0.248 * * *$ & \\
\hline SHB & $-0.135 * *$ & $3.009 * * *$ & & $0.397 * * *$ & & \\
\hline LAS & $-0.18 * *$ & $3.294 * * *$ & $0.738 * * *$ & $0.315 * *$ & & \\
\hline VND & & $2.402 * *$ & $0.786 * * *$ & $0.333 * *$ & & $-0.287 * * *$ \\
\hline SHS & & $1.893 * * *$ & $0.636 * * *$ & $0.249 * *$ & & \\
\hline BVS & $-0.136 * *$ & $3.531 * * *$ & $0.358 * * *$ & $0.397 * * *$ & & \\
\hline HUT & & $1.777 *$ & & $0.345 * * *$ & & \\
\hline PLC & $-0.234 * * *$ & $7.219 * * *$ & & $-0.222 * *$ & $0.251 * * *$ & \\
\hline HMH & $-0.124 *$ & $3.339 * *$ & & $0.831 * * *$ & & \\
\hline
\end{tabular}

Note: This table presents the Newey-West HAC standard errors and covariances test results. $V_{t}$ is the trading volume; $|\mathrm{rt}|$ is the absolute stock $\log$ return; and $\omega, \pi_{t}, \phi_{t}, \xi_{t}, \tau_{t}$, and $\varepsilon_{t}$ are as above.

$*, * *$, and $* *$ denote that the null is rejected at the $10 \%, 5 \%$, and $1 \%$ level, respectively. 
The results show that the information demand at the market level is more significantly positive than the one at the stock level for both HOSE and HNX, consistent with the correlation as reported in Table 6.

To further capture the influence of market states on the research results, a regression using dummy variables is conducted. In accordance with Ryan \& Taffler (2004), we measure two of the dummy variables denoting market states. One, in case of high return market states, takes the value 1 (for the weeks with the difference of absolute market return and the average value being greater than 1) and takes the value 0 (for the other cases). The other dummy variable, in case of low return market states, takes the value 1 and otherwise, 0 . Specifically, high return market states are defined as:

$$
\mathrm{H}_{\mathrm{t}} \equiv \mathrm{I}_{\left(\sigma_{|v|},+\infty\right)}\left(\left|v_{\mathrm{t}}\right|-\left|\overline{\mathrm{v}_{\mathrm{t}}}\right|\right)
$$

Low return market states are defined as:

$$
\mathrm{L}_{\mathrm{t}} \equiv \mathrm{I}_{\left(-\infty, \sigma_{|v|]}\right.}\left(\left|v_{\mathrm{t}}\right|-\left|\overline{v_{\mathrm{t}}}\right|\right)
$$

where I denotes an indicator function; $\left|v_{t}\right|$ is the absolute market return; $\left|\bar{v}_{\mathrm{t}}\right|$ is the average of absolute market return in the whole sample period; and $\sigma_{|v|}$ is the standard deviation of absolute market return in the whole sample period.

\section{Table 8}

Results of OLS regression between implied volatilities, information supply and

\begin{tabular}{|c|c|c|c|c|c|c|c|}
\hline Stock & $\gamma_{\mathrm{h}}$ & $\gamma_{\mathrm{t}}$ & $\delta_{\mathrm{h}}$ & $\delta_{\mathrm{t}}$ & $\zeta_{\mathrm{h}}$ & $\zeta_{\mathrm{t}}$ & $\eta_{\mathrm{h}}$ \\
\hline DPM & & & $0.101^{* *}$ & $-0.0067 * * *$ & & $-0.00643 * *$ & \\
\hline FPT & & & $-0.0644 * *$ & $-0.0038 * *$ & & & \\
\hline HPG & & & $0.276^{* *}$ & $-0.00377^{*}$ & & & \\
\hline $\mathrm{KDC}$ & $0.000224 * *$ & $-0.000353 * * *$ & & $-0.00824 * * *$ & & & \\
\hline PPC & & & & & & $-0.0156^{* *}$ & \\
\hline PVD & & & & $-0.0074 *$ & $0.000819^{* * *}$ & & \\
\hline PVT & & & & & & $-0.00078 * *$ & $-0.0749 * * *$ \\
\hline REE & & & $0.000412 * *$ & & & & \\
\hline SSI & $0.000205^{* *}$ & $0.000345^{* *}$ & $-0.00281 * * *$ & $0.00102 * * *$ & & $-0.0023^{*}$ & \\
\hline STB & & & $0.000417^{* *}$ & & & & $-0.0474 * *$ \\
\hline
\end{tabular}
demand, and market state dummy variables 


\begin{tabular}{|c|c|c|c|c|c|c|c|}
\hline Stock & $\gamma_{\mathrm{h}}$ & $\gamma_{\mathrm{t}}$ & $\delta_{\mathrm{h}}$ & $\delta_{\mathrm{t}}$ & $\zeta_{\mathrm{h}}$ & $\zeta_{\mathrm{t}}$ & $\eta_{\mathrm{h}}$ \\
\hline VIC & & & $0.0384 * * *$ & & & & \\
\hline VNM & & $-0.000036^{*}$ & & & & & $-0.0545 * * *$ \\
\hline VSH & & $-0.000198^{*}$ & & $-0.00932 * * *$ & & $0.0195 * *$ & $0.725 * *$ \\
\hline $\mathrm{ACB}$ & & & $0.000734 * *$ & & & $-0.0156^{* *}$ & \\
\hline SHB & & & $0.000744 * *$ & & $0.000819^{* * *}$ & & \\
\hline LAS & & & & & & $-0.00078 * *$ & $-0.074 * * *$ \\
\hline VND & & & & $-0.000412 * *$ & & & \\
\hline SHS & $0.000205^{* *}$ & $0.0000345^{* *}$ & $0.0000281 * *$ & $-0.00102 * * *$ & & $-0.0023 * *$ & \\
\hline BVS & & & $0.0000587 * *$ & $0.000417 * * *$ & & & $-0.0474 * *$ \\
\hline \multicolumn{8}{|l|}{ HUT } \\
\hline PLC & & $-0.000036^{*}$ & & & & & $-0.0545^{* * *}$ \\
\hline $\mathrm{HMH}$ & & $0.000198^{*}$ & $0.000102 *$ & $-0.00932 * * *$ & $0.0242 * *$ & $0.0195 * *$ & $0.7255^{* *}$ \\
\hline
\end{tabular}

Note: This table presents the Newey-West HAC standard errors and covariances test results. $\gamma_{\mathrm{h}}$ and $\gamma_{\mathrm{t}}$ are coefficients for firm-specific information demand at high and low return market states respectively; $\delta_{\mathrm{h}}$ and $\delta_{\mathrm{t}}$ are coefficients for market-related information demand at high and low return market states respectively; $\zeta_{\mathrm{h}}$ and $\zeta_{\mathrm{t}}$ are coefficients for firm-specific information supply at high and low return market states respectively; and $\eta_{\mathrm{h}}$ and $\eta_{\mathrm{t}}$ are coefficients for market-related information supply at high and low return market states respectively.

$*, * *$, and $* *$ denote that the null is rejected at the $10 \%, 5 \%$, and $1 \%$ level, respectively.

Estimated results of the RV model are presented in Table 8, the contents of which only cover the estimated coefficients of information supply and/or demand while exclude the results of other control variables such as market return, first lag, or lag of RV. Table 8's results are compatible with those of the correlation analyses. In short, the impact on RV produced by information demand is more statistically significant in low return market states than that in high ones. The coefficients of market-related information demand are significant in most of the cases.

We assume that practical reasons could be found, complying with the results of a negative relationship between information demand and market volatilities as indicated above. As with a relatively small-scaled market compared to foreign economies, low liquidity, and dominant participation of institutional investors rather than individual ones, speculative behaviors are more likely to be exhibited in stock markets. Signs of 
market speculation can be readily identified with a rising rate market which gains high return but low liquidity, or otherwise with a falling rate market, low return, and high liquidity.

During the course of rising rates most market participants are institutional investors, whereas the falling rate moments witness the presence of individual ones, those who grasp less or later information than professional institutions, which may reasonably be attributable to the increasingly higher information demand upon low market return. Yet, more extensive research specifically on this nexus is needed to further clarify the above findings, and within the scope of this study, we have merely brought into discussion the issue based on empirical observations of the stock markets in the 20082014 period.

\section{Conclusions}

In this study we focus on the analysis of information demand of individual investors and volatilities of Vietnam's stock market by controlling for such factors as information supply, market return, and lags of realized and conditional volatilities as in the GARCH $(1,1)$ approach. Based on SVI provided by Google Trends, we estimate investor's information demand through a sample of 22 stock tickers selected from the stocks listed on both HOSE and HNX. Overall, the results demonstrate a positive signal sent from the increasing number of investors with their presence in the Vietnam's stock market in terms of both in qualitative and quantitative perspectives. This bespeaks the Vietnam's stock market on its right track along its gradual development and improvement.

Certain limitations of the study cannot be avoided. First, insufficient and/or imprecise information disclosures appear to hinder our data collection. Despite the information retrieval from different channels such as financial pages and various firms' websites, there has been a lack of the information supply. Second, the survey on such a small sample size as VN30 and HNX30 in the seven-year period has yet to generalize the effects of information supply and demand on price movements in each specific economic sector. These are thus expected to be overcome in the future studies. 


\section{Recommendations}

The research findings demonstrate that both information supply and demand have exerted impact on market volatilities. More powerful effects are also produced by information demand; particularly, the demand at the market level is proved to be more significant than that at each single stock level in not only realized but also conditional volatilities. It has also been found that a negative relationship exists between information demand and market volatilities. The underlying reason for this refers to the fact that an increase in individual investor's information demand is synonymous with more market participants and thereby with improved liquidity, less price movements, and more effective market operations.

This is more robust when the nexus between information demand and trading volume is highly significantly positive, and is even stronger in low return market states. The higher trading volume amid less market volatilities partly signals investor's reluctance to take risk. More investment during market stability is prioritized to escape being trapped by speculative behaviors. Therefore, the government in its expanding the stock market and attracting investment should take measures to restrict the number of individuals or organizations as speculators in the market.

In a nutshell, the increasing presence of investors in Vietnam's stock market in quantitative and qualitative perspectives positively signals that the market has been on its right path and is little by little developed and improved. Hence, to keep pace with the development of other foreign stock markets, it is essential that the government adopt appropriate strategies particularly aiming at the demand of individual investors, who should be motivated by a high degree of market transparency facilitated by improved financial information systems. Several recommendations to the government can accordingly be considered as follows:

- Radically improving market management: The market management agencies shall be subject to frequent inspection and transaction monitoring that aid the course (while prevent) information transparency (asymmetry) besides strictly controlling and eliminating a spate of insider trading involved in market manipulation.

- Fostering the restructuring in accordance with the scheme on "restructuring of the securities market and insurance companies" (Vietnamese Government, 2012) that considers the merger of HOSE and HNX, ensuring uniformity across market transactions. 
- Providing stock investors with universal knowledge, organizing short- / mediumterm training and seminars on economic situations that have them well-equipped with clear insights and indirectly exert a driving force on the market

\section{References}

Allen, B. (1990). Information as an economic commodity. The American Economic Review, 80(2), $268-273$.

Andersen, T. G., Bollerslev, T., Diebold, F. X., \& Ebens, H. (2001a). The distribution of realized stock return volatility. Journal of Financial Economics, 61, 43-76.

Andersen, T. G., Bollerslev, T., Diebold, F. X., \& Labys, P. (2001b). The distribution of realized exchange rate volatility. Journal of the American Statistical Association, 96, 42-55.

Bollerslev, T. (1986). Generalized autoregressive conditional heteroskedasticity. Journal of Econometrics, 31, 307-327.

Bomfim, A. N. (2001). Pre-announcement effects, news effects, and volatility: Monetary policy and the stock market. Journal of Banking and Finance, 27, 133-151.

Clark, P. K. (1973). A subordinated stochastic process model with finite variance for speculative prices. Econometrica, 41(1), 135-155.

Da, Z., Engelberg, J., \& Gao, P. (2011a). In search of attention. The Journal of Finance, 66(5), 1461-1499.

Da, Z., Engelberg, J., \& Gao, P. (2011b). The sum of all FEARS: Investor sentiment and asset prices. Review of Financial Studies, 28(1), 1-32.

Da, Z., Engelberg, J., \& Gao, P. (2011c). In search of fundamentals. AFA 2012 Chicago Meetings Paper.

Dickey, D. A., \& Fuller, W. A. (1979). Distribution of the estimators for Autoregressive Time Series with a unit root. Journal of the American Statistical Association, 74(366), 427-443.

Ederington, L. H., \& Lee, B. H. (1993). How markets process information: News releases and volatility. Journal of Finance, 48(4), 1161-1191.

Epps, T. W., \& Epps, M. L. (1973). The stochastic dependence of security price changes and transaction volumes: Implications for the mixture of distributions hypothesis. Econometrica, 44, 305-321.

Fama, E. F., Fisher, L., Jensen, M. C., \& Roll, R. (1969). The adjustment of stock prices to new information. International Economic Review, 10, 1-21.

Fink, C., \& Johann, T. (2013). May I have your attention, please: The market microstructure of investor attention (Working paper). University of Mannheim 
French, K. R., \& Roll, R. (1986). Stock return variances: The arrival of information and the reaction of traders. Journal of Financial Economics, 17, 5-26.

Grossman, S. J., \& Stiglitz, J. E. (1980). On the impossibility of informationally efficient markets. The American Economic Review, 70(3), 393-408.

Huang, T. L., Chen, M. L., Kuo, H. J., \& Lai, K. L. (2013). Information demand revealed by Google Search Engine and speculative trading activities in the capital market (Working paper). Kaohsiung, Taiwan: National Sun Yat-Sen University.

Investopedia. (n/d). Asymmetric information. Retrieved from http://www.investopedia.com/terms/a/asymmetricinformation.asp

Kalev, P., Liu, W., Pham, P. K., \& Jarnecic, E. (2004). Public information arrival and volatility of intraday stock returns. Journal of Banking and Finance, 28, 1441-1467.

Karpoff, J. M. (1987). The relation between price changes and trading volume: A survey. Journal of Financial and Quantitative Analysis, 22(1), 109-126.

Kihlstrom, R. (1974). A general theory of demand for information about product quality. Journal of Economic Theory, 8, 413-439.

Phillips, P., \& Perron, P. (1988). Testing for a unit root in time series regression. Biometrika, 75(2), 335-346.

Radner, R., \& Stiglitz, J. E. (1984). A nonconcavity in the value of information. In M. Boyer \& R. Kihlstrom (eds.), Bayesian Models of Economic Theory (pp. 33-52). Amsterdam: Elsevier Science Publishers.

Ryan, P., \& Taffler, R. J. (2004). Are economically significant stock returns and trading volumes driven by firm-specific news releases? Journal of Business Finance and Accounting, 31, 49-82.

Tauchen, G. E., \& Pitts, M. (1983). The price variability - volume relationship on speculative markets. Econometrica, 51(2), 485-505.

Vietnamese Government. (2012). Decision No. 1826/QD-TTg on approval for the scheme on "restructuring of the securities market and insurance companies". Retrieved from http://vbqppl.mpi.gov.vn/en-us/Pages/default.aspx?itemId=f0159097-f9af-411b-95cc$4674183 \mathrm{c} 737 \&$ list $=$ documentDetail

Vlastakis, N., \& Markellos, R. N. (2012). Information demand and stock market volatility. The Journal of Banking \& Finance, 36(6), 1808-1821.

Wikipedia. (n/d). Google Trends. Retrieved from http://en.wikipedia.org/wiki/Google_Trends

Xu, S. Y. (2012). Stock price forecasting using information from Yahoo Finance and Google Trend (Working paper). Berkeley: University of California. 